\title{
Effects of blue light and caffeine on mood
}

\author{
Johan G. Ekström • C. Martyn Beaven
}

Received: 16 October 2013 / Accepted: 10 February 2014 / Published online: 4 March 2014

(C) Springer-Verlag Berlin Heidelberg 2014

\begin{abstract}
Rationale Both short wavelength (blue) light and caffeine have been studied for their mood enhancing effects on humans. The ability of blue light to increase alertness, mood and cognitive function via non-image forming neuropathways has been suggested as a non-pharmacological countermeasure for depression across a range of occupational settings.

Objectives This experimental study compared blue light and caffeine and aimed to test the effects of blue light/placebo (BLU), white light/240-mg caffeine (CAF), blue light/240-mg caffeine (BCAF) and white light/placebo (PLA), on mood. Methods A randomised, controlled, crossover design study was used, in a convenience population of 20 healthy volunteers. The participants rated their mood on the Swedish Core Affect Scales (SCAS) prior to and after each experimental condition to assess the dimensions of valence and activation. Results There was a significant main effect of light $(\mathrm{p}=$ 0.009), and the combination of blue light and caffeine had clear positive effects on core effects (ES, ranging from 0.41 to 1.20 ) and global mood (ES, $0.61 \pm 0.53$ ).

Conclusions The benefits of the combination of blue light and caffeine should be further investigated across a range of applications due to the observed effects on the dimensions of arousal, valence and pleasant activation.
\end{abstract}

Keywords Arousal $\cdot$ Valence $\cdot$ Phototherapy $\cdot$ Drug potentiation

J. G. Ekström $(\bowtie)$

Nationellt Vintersportcentrum, Department of Psychology, Mid

Sweden University, 83125 Östersund, Sweden

e-mail: johan.ekstrom@jll.se

C. M. Beaven

Swedish Winter Sports Research Centre, Department of Health

Sciences, Mid Sweden University, Östersund, Sweden

\section{Introduction}

Decades of research have been spent on investigating how to enhance mood. It is a highly relevant aspect when considering healthy human functioning in many different settings and has the potential to benefit a wide range of applications such as educational, occupational and human health environs and even sporting performance. During the last two decades, a renewed interest in the effects of light on cognitive performance and mood has emerged. There is now compelling evidence of a non-image forming visual system (NIF)which is dependent on light for regulation of neuroendocrine and neurobehavioural functions in humans (Perrin et al. 2004; Vandewalle et al. 2006). Specific melanopsin-sensitive photoreceptors have been identified that are capable of maintaining NIF functions, such as pupillary light reflex and photoentrainment of the circadian rhythms, even when classical photoreceptors are lost (Hattar et al. 2002; Berson 2003).

It is now well known that the NIF visual system is most sensitive to wavelengths at approximately $460 \mathrm{~nm}$, which is perceived as blue light (Brainard et al. 2001; Berson et al. 2002; Hatori and Panda 2010). This can be contrasted with the visual forming system in which the cones are most sensitive to wavelengths of $555 \mathrm{~nm}$, corresponding to the human perception of the colour green (Lockley et al. 2003). The practical relevance of the NIF visual system is highlighted in studies on blind humans, lacking functional outer retinae and light perception, that demonstrate that exposure to specific wavelength light increases brain activity in prefrontal areas and induces melatonin suppression (Czeisler et al. 1995; Zaidi et al. 2007). Blue light serves as a modulator of many human functions, such as alertness (Cajochen et al. 2000; Revell et al. 2006), arousal (Vandewalle et al. 2007), reaction time in cognitive tasks (Chellappa et al. 2011), work performance (Mills et al. 
2007) and mood (Lee et al. 1997; Glickman et al. 2006; Viola et al. 2008; Iskra-Golec et al. 2012). It is also noteworthy that the positive effects of light on mood have shown to be applicable in clinical psychology and psychiatry, such as in treatment of non-seasonal depression (Golden et al. 2005; Lieverse et al. 2011) and seasonal affective disorder (Glickman et al. 2006; Meesters et al. 2011).

The effects of caffeine on different aspects of human well-being are well explored (Fredholm et al. 1999), and habitual coffee drinkers have been reported to a have a decreased risk for depression (Lara 2010; Ruusunen et al. 2010; Lucas et al. 2011). In addition to the consistently reported effects on alertness, cognitive function and reaction times (Lieberman et al. 1987; Warburton et al. 2001; Childs and Wit 2006), caffeine has also been demonstrated to enhance mood (Smit and Rogers 2000; Haskell et al. 2005; Smith 2009). On the other hand, higher doses of caffeine have been associated with negative symptoms such as tension, nervousness and anxiety (Kaplan et al. 1997; Rogers 2007), as well as increased sleep latency and decreased sleep quality (Sicard et al. 1996). Caffeine consumption has also been associated with the induction of psychiatric symptoms (Broderick and Benjamin 2004).

Although caffeine and blue light share a range of similar effects and have been clinically implemented, their combined effects are not fully understood. One recent study assessed the effects of blue light and caffeine on cognitve function, demonstrating differential effects on executive function, while a cumulative effect was observed on performance in a visual psychomotor test (Beaven and Ekström 2013). The current study aimed to investigate the acute effects of blue light and caffeine on mood and alertness and further compared the effects of a combination of blue light and caffeine to blue light on the core affect dimensions of valence and activation. The following hypotheses were formulated:

1. Exposure to blue light and a placebo pill would have a positive effect on mood compared to subjects exposed to the polychromatic white light and placebo pill condition.

2. Caffeine ingestion $(240 \mathrm{mg})$ and exposure to polychromatic white light would have a positive effect on mood compared to the white light and placebo pill condition.

3. Caffeine ingestion $(240 \mathrm{mg})$ and polychromatic white light exposure would have different effects on mood compared to the blue light and placebo pill condition.

4. The combination of exposure to blue light and caffeine ingestion $(240 \mathrm{mg}$ ) would demonstrate larger effects on mood than the blue light and placebo pill, polychromatic white light and placebo, and polychromatic white light and caffeine ingestion $(240 \mathrm{mg})$ conditions.

\section{Method}

Participants

The study recruited 24 subjects ( 13 males, 11 females) from the Mid-Sweden region $(m=26, S D=4$ years). The participants were recruited by e-mailing all students on the Mid-Sweden University, campus Östersund. All participants were nonsmokers, low to moderate caffeine and alcohol consumers and were not on any contraindicatory medication. Participants were excluded from participating if they had worked night shifts during the last year, had travelled through more than 1 time zone during the last 2 months or reported a medical condition likely to compromise the study results. Before participation, each participant signed an informed consent for full understanding of the experiments, with pre-approval obtained from the Regional Ethical Review Board (Application \#2012318-31 M). No financial compensation was provided.

Design

A randomised, controlled, crossover design study was used. The study consisted of 2 independent variables (light and caffeine). These had each 2 conditions (blue or white; caffeine or non-caffeine). Pre- and post-intervention data were collected. Thus, the experimental design was a 2 (blue or white light $) \times 2$ (caffeine or placebo $) \times 2$ (pre and post) . Accordingly, there were four trial conditions: white light/ placebo (PLA), white light/240-mg caffeine (CAF), blue light/placebo (BLU) and blue light/240-mg caffeine (BCAF). Counterbalancing was used to control for order effects. The caffeine/placebo distribution was double-blinded.

\section{Procedure}

The current study was performed during winter season in Östersund, Sweden $\left(63.1^{\circ} \mathrm{N}\right)$, starting in the end of February until the beginning of April. The laboratory experiments were conducted in the early evening (5:00 to 7:00 p.m.) and lasted for $1 \mathrm{~h}$. Each participant was scheduled to perform experimental trials on four occasions, within a 1-month time period. Note that the the menstrual phase of the female participants was not controlled for. Subjects were asked to refrain from caffeine, strenous exercise and alcohol on the experimental days.

The participants were instructed to rate their mood on the Swedish Core Affect Scales (SCAS). The participants then ingested a gelatine capsule containing either caffeine $(240 \mathrm{mg})$ or a visually indistinguishable sugar placebo $(300 \mathrm{mg})$, before entering the experimental room. The experimental room was a specially designed room, decorated to suit the purposes of the experiment. It contained four comfortable chairs, the walls hung with draperies and wall-to-wall carpet. The temperature 
Table 1 The 12 bipolar adjectives used in SCAS

\begin{tabular}{llll}
\hline Valence & Arousal & Pleasant activation & Unpleasant activation \\
\hline displeased-pleased & sleepy-awake & bored-interested & tense-serene \\
sad-glad & dull-peppy & indifferent-engaged & anxious-calm \\
depressed-happy & passive-active & pessimistic-optimistic & nervous-relaxed \\
\hline
\end{tabular}

in the room was controlled at a constant $20 \pm 0.5{ }^{\circ} \mathrm{C}$. No pharmacological intervention was used to influence pupil dilation or responsiveness. Until entering the experimental room, the participants were unaware of the light stimulus they would be exposed to: either a $\sim 40 \mathrm{~lx}$ of blue light from a commercially available LED light source (Techlight ${ }^{\circledR}$ RGB, $3 \mathrm{~W}, \lambda \max =470 \mathrm{~nm})$ or the white light alternative $(\sim 100 \mathrm{~lx})$ for $1 \mathrm{~h}$.

The participants were instructed to stay awake and to keep their eyes open while remaining comfortably seated. Every $15 \mathrm{~min}$, a researcher entered the room to ensure subject compliance. At the end of the $1 \mathrm{~h}$, the participants again completed the SCAS. A 1-h intervention time was chosen in order to match the light exposure time to the absorption time of caffeine as the peak concentration of plasma caffeine after a normal intake is between 15 and 120 min after oral ingestion (Fredholm et al. 1999) and the greatest effect of caffeine is approximately $1 \mathrm{~h}$ after intake in a previous study by Lieberman et al. (2002). In previous studies of blue light, duration of exposure varies from less than $1 \mathrm{~min}$ up to $8 \mathrm{~h}$. It has been demonstrated that just $50 \mathrm{~s}$ of short-wave light exposure can cause detectable effects in the hippocampus and amygdala (Vandewalle et al. 2007), while Viola et al. (2008) reported positive effects in an occupational setting with full-length working days of blue-enriched white light exposure. Note that the selected light intensity ( 40 lx) in the current study has been shown previously to induce an alerting effect after a 1-h exposure (Figueiro and Rea 2010).

\section{Mood}

Research indicates that mood can be measured by using emotion adjectives on self-reported questionnaires on two dimensions in a circumplex (Reisenzein 1994; Lang 1995; Cacioppo et al. 1999). The Swedish Core Affect Scales (SCAS; Västfjäll and Gärling 2007) was used to measure core affects, which are defined as "cognitively accessible elements of a current mood, an emotional reaction, or an anticipated emotional reaction" (Västfjäll et al. 2002). The questionnaire consisted of 12 bipolar adjectives (Table 1) shown on a visual analogue scale (VAS). The SCAS uses two dimensions, valence and activation, when measuring mood. The intermediate dimension of the positive affect of valence and activation is named pleasant activation, whereas the negative counterpart is labelled unpleasant deactivation. The intermediate dimension of positive valence but negative activation is labelled pleasant deactivation, whereas the negative valence and positive activation is labelled unpleasant activation (Västfjäll et al. 2002). Thus, adjective pairs are presented that relate to one of the four sub-scales: valence, arousal, pleasant activation and unpleasant deactivation. The greater the score on the each scale, the more positive was the assessed mood of the subject.Herein, we explicitly define the summed score of the four sub-scales on the SCAS as 'Global Mood'. The SCAS has reported Cronbach $\alpha$ 's ranging from 0.62 to 0.93 (Västfjäll et al. 2002).

\section{Statistical analyses}

IBM $^{\circledR}{ }^{\circledR}$ SPSS ${ }^{\circledR}$ Statistics Version 20.0 was used for the statistical calculations. Repeated measures analysis of variance (rANOVA) was used to compare the pre- and post-data from the four experimental conditions. Bonferroni corrections were applied to post hoc tests for the pairwise comparisons. The assumption of sphericity was not violated in any of the

Table 2 Means for BLU, CAF, BCAF and PLA on SCAS sub-scales registered after each experimental condition

\begin{tabular}{|c|c|c|c|c|}
\hline \multirow[b]{2}{*}{ Variable } & \multicolumn{4}{|c|}{ Experimental condition } \\
\hline & PLA & BLU & $\mathrm{CAF}$ & BCAF \\
\hline Global mood & $77.5(9.9)^{* *}$ & $80.9(11.7)$ & $77.7(13.2)^{*}$ & $85.5(9.0)$ \\
\hline Valence & $20.9(2.5)$ & $21.2(2.5)$ & $20.3(3.2)^{*}$ & $22.2(2.1)$ \\
\hline Arousal & $15.1(4.3)^{* *}$ & $17.9(3.9)$ & $16.9(5.4)$ & $19.1(3.6)$ \\
\hline Pleasant activation & $19.9(3.4)$ & $20.0(3.6)$ & $19.7(4.0)$ & $21.8(2.9)$ \\
\hline Unpleasant deactivation & $21.7(3.0)$ & $21.9(3.8)$ & $20.8(4.2)$ & $22.5(2.7)$ \\
\hline
\end{tabular}

$P L A$ white light/placebo, $C A F$ white light/240-mg caffeine, $B L U$ blue light/placebo, $B C A F$ blue light/240-mg caffeine. Parentheses represent standard deviations. ${ }^{*} p<0.05$ vs. BCAF condition; $* * p<0.01$ vs. BCAF condition 
Table 3 Pairwise comparisons are displayed for testing hypotheses 1 to 3

\begin{tabular}{|c|c|c|c|c|c|c|}
\hline \multirow[b]{2}{*}{ Variable } & \multicolumn{2}{|c|}{ BLU vs. PLA } & \multicolumn{2}{|c|}{ CAF vs. PLA } & \multicolumn{2}{|c|}{ BLU vs. CAF } \\
\hline & $F$ & $p$ value & $F$ & $p$ value & $F$ & $p$ value \\
\hline Global mood & 1.51 & 0.234 & 0.00 & 0.948 & 1.64 & 0.216 \\
\hline Valence & 0.31 & 0.584 & 0.68 & 0.420 & 2.04 & 0.169 \\
\hline Arousal & 4.19 & 0.055 & 3.11 & 0.094 & 0.44 & 0.517 \\
\hline Pleasant activation & 0.01 & 0.907 & 0.05 & 0.821 & 0.11 & 0.748 \\
\hline Unpleasant deactivation & 0.10 & 0.759 & 0.88 & 0.360 & 1.73 & 0.204 \\
\hline
\end{tabular}

$P L A$ white light/placebo, $C A F$ white light/240-mg caffeine, $B L U$ blue light/placebo

performed rANOVAS, tested with Mauchly's sphericity test. There were no missing values for any of the dependent variables; thus, no statistical attrition analysis was made. Magnitudes of the standardised effects (Cohen effect size [ES]) were interpreted using thresholds of $0.2,0.6,1.2$ and 2.0 for small, moderate, large and very large, respectively (Hopkins et al. 2009). An effect was deemed unclear if the confidence interval overlapped the thresholds for both small positive and small negative effects. The significance level was set at $p \leq 0.05$.

\section{Results}

Two participants failed to complete all four experimental trials, and two subjects were excluded because of night shift work or travel at some occasion during the study. There was a significant main effect of light, $F(1,19)=8.35$, $p=0.009$, but not for caffeine, $F(1,19)=0.40, p=0.537$, or time, $F(1,19)=0.07, p=0.797$ on mood. The means and standard deviations for the dependent post-measures are displayed in Table 2.

There were no reliable interaction effects in the main analysis between light $\times$ caffeine $F(1,19)=2.42, p=0.136$, light $\times$ time, $F(1,19)=0.87, p=0.362$, caffeine $\times$ time, $F(1,19)=1.52$, $p=0.233$, or light $\times$ caffeine $\times$ time, $F(1,19)=0.15, p=0.703$. Pairwise comparisons for global mood and the four dimensional sub-scales resultant from the three conditions BLU, CAF and PLA are displayed in Table 3.

Further pairwise comparisons revealed that the participants reported a more positive global mood when there had a combination of blue light and caffeine (BCAF), compared to blue light and placebo (BLU), $F(1,19)=4.73, p=0.043, \eta_{p}{ }^{2}=$ 0.20 , caffeine and white light $(\mathrm{CAF}), F(1,19)=13.52, p=$ $0.002, \eta_{p}{ }^{2}=0.42$, and white light and placebo (PLA), $F(1$, $19)=11.78, p=0.003, \eta_{p}{ }^{2}=0.38$. Figure 1 illustrates the condition-induced differences on the SCAS assessments with pre-intervention subtracted from post-intervention. Only the BCAF condition elicited a moderate improvement in mood (ES, $0.61 \pm 0.53$ ).

\section{Discussion}

Here, our randomised, controlled, crossover study revealed a potentiated effect of blue light and caffeine on global mood as well as the specific dimensions of arousal, valence and pleasant activation. An enhancement in global mood could be observed after 1-h exposure to blue light when combined with $240 \mathrm{mg}$ of caffeine. Similarly, although not significant at the 0.05 level, there were clear trends towards elevating arousal effects of both the BLU and CAF conditions compared to PLA. These results are in line with with previous research that investigated the effects of blue light (Viola et al. 2008) and caffeine (Haskell et al. 2005) on mood individually.

It was hypothesised that blue light and caffeine would demonstrate different effects on aspects of mood on the core affect scale. While previous studies have tested the effects of caffeine and blue light on mood separately (Haskell et al. 2005; Childs and Wit 2006; Viola et al. 2008; Iskra-Golec et al. 2012), no data is available on any combined effects. The combination of bright white light and caffeine, however, has been previously demonstrated to suppress melatonin and

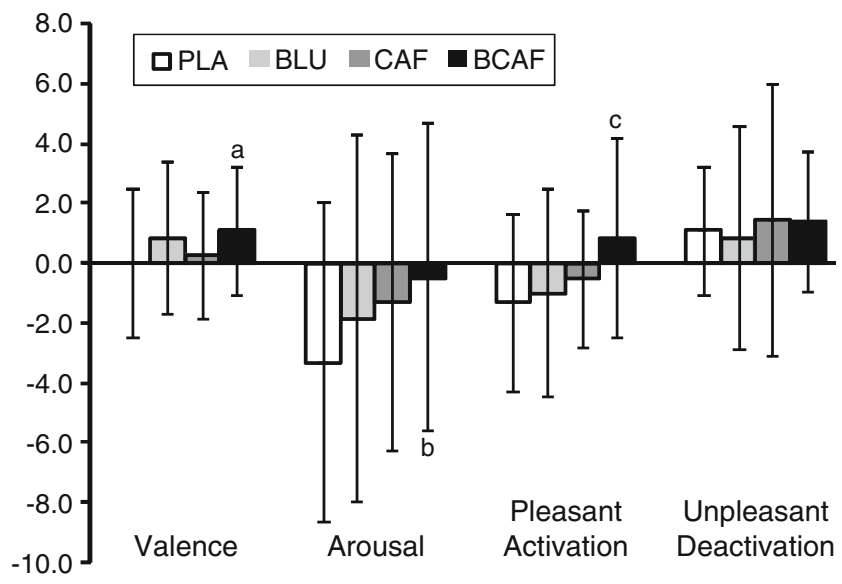

Fig. 1 Differences between mood resultant from the experimental conditions $P L A$ white light/placebo, $C A F$ white light/240-mg caffeine, $B L U$ blue light/placebo, $B C A F$ blue light/240-mg caffeine. a substantially different to PLA (ES, 0.41), $b$ substantially different to PLA (ES, 1.20), $c$ substantially different to PLA (ES, 0.82). Error bars represent SD 
enhance cognitive performance to a greater extent than either intervention alone (Wright Jr et al. 1997, 2000). Previous work has demonstrated distinct effects of blue light expsosure and caffeine dose on cognitive tasks that assessed different components of psychomotor function suggestive of differing mechanisms of action (Beaven and Ekström 2013). The absence of a ceiling effect in the current study corroborates these findings. The current study did detect post-intervention differences between the CAF and BCAF conditions in the valence dimension that were not apparent when comparing BCAF and BLU. In the context of our results, this observation may reflect anxious arousal (Nitschke et al. 2001) which were less evident in the blue light conditions.

The mechanisms by which the effects of caffeine on mood are realised have been investigated, with blockade of adenosine A1 and A2 receptors in the brain being particularly relevant given the known functional connectivity between adenosine receptors and the dopaminergic system (Fredholm et al. 1999; Boutrel and Koob 2004; Winston et al. 2005). Although this study did not specifically investigate underlying mechanisms, the blue light results may be considered in relation to what Rautkylä, Puolakka and Halonen (2012) propose as a hypothetical model of two NIF pathways whereby direct visual input from the retina is projected in to the amygdala. The importance of a dual pathway for the effects of light on human function is highlighted by the known role of the amygdala in emotion processing (Phelps 2006).

Despite the double-blinded study design, we cannot discount the possibility that some participants were conscious of the physiological stimulatory actions of caffeine and adjusted their subsequent self-assessment accordingly. Further, we acknowledge that the absolute, rather than relative doses of caffeine may have contributed to differences in peak caffeine levels in the individuals and that habitual caffeine consumption was not strictly assessed. However, recent research suggests that there is no association between habitual caffeine intake and peak or total serum caffeine concentrations (Skinner et al. 2013). Indeed, it has been suggested that individual differences in caffeine sensitivity are more likely a result of intrinsic differences in responsiveness to caffeine at sites of action in the brain, rather than from differences in absorption, distribution or metabolism of the substance (Goldstein et al. 1965). It should be noted that, in contrast to many studies investigating the effects of caffeine or light on mood (Lieberman et al. 2002; Phipps-Nelson et al. 2003; Rüger et al. 2006), the present study did not sleep deprive participants, thus improving the ecological validity of the study results. It has been suggested that many of the effects of caffeine constitute a return to normal function, or an amelioration of the effects of caffeine withdrawal (Rogers 2007). However, a number of researchers have demonstrated that caffeine has psychoactive effects even in the absence of withdrawal (Warburton et al. 2001; Smith et al. 2005; Childs and
Wit 2006), and work by Smit and Rogers (2000) argues against this 'withdrawal reversal' hypothesis.

The environment in which we evolved and developed our innate physiology, is vastly different to the biotope in which the vast majority of civilised humans now inhabit. Various effects of artificial exposure to blue light on our physiology have been recently documented (Cajochen et al. 2011; Wood et al. 2013). Further, appropriate lighting is associated with improved human health in hospital environments (Walch et al. 2005; Joarder and Price 2013), behavioural therapy (Golden et al. 2005; Morin et al. 2006), academic performance (Heschong et al. 2002; Mott et al. 2012) and workplace well-being (Viola et al. 2008; Iskra-Golec et al. 2012). The potentiating effects of blue light exposure when used in conjunction with caffeine on mood noted herein further demonstrate the importance of these convenient and accessible biomodulators in human functioning and performance.

\section{References}

Beaven CM, Ekström JG (2013) A comparison of blue light and caffeine effects on cognitive function and alertness in humans. PLoS One 8: e76707

Berson DM (2003) Strange vision: ganglion cells as circadian photoreceptors. Trends Neurosci 26:314-320

Berson DM, Dunn FA, Takao M (2002) Phototransduction by retinal ganglion cells that set the circadian clock. Science 295:1070-1073

Boutrel B, Koob GF (2004) What keeps us awake: the neuropharmacology of stimulants and wakefulness-promoting medications. Sleep 27:1181-1194

Brainard GC, Hanifin JP, Greeson JM, Byrne B, Glickman G, Gerner E et al (2001) Action spectrum for melatonin regulation in humans: evidence for a novel circadian photoreceptor. J Neurosci 21:6405-6412

Broderick P, Benjamin AB (2004) Caffeine and psychiatric symptoms: a review. J Okla State Med Assoc 97:538-542

Cacioppo JT, Gardner WL, Berntson GG (1999) The affect system has parallel and integrative processing components: form follows function. J Pers Soc Psychol 76:839-855

Cajochen C, Zeitzer JM, Czeisler CA, Dijk DJ (2000) Dose-response relationship for light intensity and ocular and electroencephalographic correlates of human alertness. Behav Brain Res 115:75-83

Cajochen C, Frey S, Anders D, Späti J, Bues M, Pross A et al (2011) Evening exposure to a light-emitting diodes (LED)-backlit computer screen affects circadian physiology and cognitive performance. J Appl Physiol 110:1432-1438

Chellappa SL, Steiner R, Blattner P, Oelhafen P, Götz T, Cajochen C (2011) Non-visual effects of light on melatonin, alertness and cognitive performance: can blue-enriched light keep us alert? PLoS One 26:e16429

Childs E, Wit H (2006) Subjective, behavioral, and physiological effects of acute caffeine in light, nondependent caffeine users. Psychopharmacology 185:514-523

Czeisler CA, Shanahan TL, Klerman EB, Martens H, Brotman DJ, Emens JS et al (1995) Suppression of melatonin secretion in some blind patients by exposure to bright light. N Engl J Med 332:6-11

Figueiro MG, Rea MS (2010) The effects of red and blue lights on circadian variations in cortisol, alpha amylase, and melatonin. Int $\mathbf{J}$ Endocrinol 829351 
Fredholm BB, Bättig K, Holmén J, Nehlig A, Zvartau EE (1999) Actions of caffeine in the brain with special reference to factors that contribute to its widespread use. Pharmacol Rev 51:83-133

Glickman G, Byrne B, Pineda C, Hauck WW, Brainard GC (2006) Light therapy for seasonal affective disorder with blue narrow-band lightemitting diodes (LEDs). Biol Psychiatry 59:502-507

Golden RN, Gaynes BN, Ekstrom RD, Hamer RM, Jacobsen FM, Suppes Tet al (2005) The efficacy of light therapy in the treatment of mood disorders: a review and meta-analysis of the evidence. Am J Psychiatry 162:656-662

Goldstein A, Warren R, Kaizer S (1965) Psychotropic effects of caffeine in man I. Individual differences in sensitivity to caffeine-induced wakefulness. J Pharmacol Exp Ther 149:156-159

Haskell CF, Kennedy DO, Wesnes KA, Scholey AB (2005) Cognitive and mood improvements of caffeine in habitual consumers and habitual non-consumers of caffeine. Psychopharmacology 179:813-825

Hatori M, Panda S (2010) The emerging roles of melanopsin in behavioral adaptation to light. Trends Mol Med 16:435-446

Hattar S, Liao HW, Takao M, Berson DM, Yau KW (2002) Melanopsincontaining retinal ganglion cells: architecture, projections, and intrinsic photosensitivity. Science 295:1065-1070

Heschong L, Wright RL, Okura S (2002) Daylighting impacts on human performance in school. J Illum Eng Soc N Am 101-114

Hopkins WG, Marshall SW, Batterham AM, Hanin J (2009) Progressive statistics for studies in sports medicine and exercise science. Med Sci Sports Exerc 41:3-12

Iskra-Golec IM, Wazna A, Smith L (2012) Effects of blue-enriched light on the daily course of mood, sleepiness and light perception: a field experiment. Light Res Technol 44:506-513

Joarder AR, Price ADF (2013) Impact of daylight illumination on reducing patient length of stay in hospital after coronary artery bypass graft surgery. Light Res Technol 45:435-449

Kaplan GB, Greenblatt DJ, Ehrenberg BL, Goddard JE, Cotreau MM, Harmatz JS et al (1997) Dose-dependent pharmacokinetics and psychomotor effects of caffeine in humans. J Clin Pharmacol 37:693-703

Lang PJ (1995) The emotion probe: studies of motivation and attention. Am Psychol 50:372-385

Lara DR (2010) Caffeine, mental health, and psychiatric disorders. J Alzheimers Dis 20:239-248

Lee TM, Chan CC, Paterson JG, Janzen HL, Blashko CA (1997) Spectral properties of phototherapy for seasonal affective disorder: a metaanalysis. Acta Psychiatr Scand 96:117-121

Lieberman HR, Wurtman RJ, Emde GG, Roberts C, Coviella ILG (1987) The effects of low doses of caffeine on human performance and mood. Psychopharmacology 92:308-312

Lieberman HR, Tharion WJ, Shukitt-Hale B, Speckman KL, Tulley R (2002) Effects of caffeine, sleep loss, and stress on cognitive performance and mood during U.S. Navy SEAL training. Sea-AirLand. Psychopharmacology 164:250-261

Lieverse R, Van Someren EJ, Nielen MM, Uitdehaag BM, Smit JH, Hoogendijk WJ (2011) Bright light treatment in elderly patients with nonseasonal major depressive disorder: a randomized placebo-controlled trial. Arch Gen Psychiatr 68:61-70

Lockley SW, Brainard GC, Czeisler CA (2003) High sensitivity of the human circadian melatonin rhythm to resetting by short wavelength light. J Clin Endocrinol Metab 88:4502-4505

Lucas M, Mirzaei F, Pan A, Okereke OI, Willett WC, O'Reilly EJ et al (2011) Coffee, caffeine, and risk of depression among women. Arch Intern Med 171:1571-1578

Meesters Y, Dekker V, Schlangen L, Bos E, Ruiter M (2011) Lowintensity blue-enriched white light (750 lux) and standard bright light (10 000 lux) are equally effective in treating SAD. A randomized controlled study. BMC Psychiatr 11:17

Mills PR, Tomkins SC, Schlangen LJM (2007) The effect of high correlated colour temperature office lighting on employee wellbeing and work performance. J Circadian Rhythm 5
Morin CM, Bootzin RR, Buysse DJ, Edinger JD, Espie CA, Lichstein KL (2006) Psychological and behavioral treatment of insomnia:update of the recent evidence (1998-2004). Sleep 29:1398-1414

Mott MS., Robinson DH., Walden A., Burnette J., Rutherford AS (2012) Illuminating the effects of dynamic lighting on student learning. SAGE Open

Nitschke JB, Heller W, Imig JC, McDonald RP, Miller GA (2001) Distinguishing dimensions of anxiety and depression. Cogn Ther Res 25:1-22

Perrin F, Peigneux P, Fuchs S, Verhaeghe S, Laureys S, Middleton $B$ et al (2004) Nonvisual responses to light exposure in the human brain during the circadian night. Curr Biol 14:18421846

Phelps EA (2006) Emotion and cognition: insights from studies of the human amygdala. Ann Rev Psychol 57:27-53

Phipps-Nelson J, Redman JR, Dijk DJ, Rajaratnam SM (2003) Daytime exposure to bright light, as compared to dim light, decreases sleepiness and improves psychomotor vigilance performance. Sleep 26: 695-700

Rautkylä E, Puolakka M, Halonen L (2012) Alerting effects of daytime light exposure - a proposed link between light exposure and brain mechanisms. Light Res Technol 44:238-252

Reisenzein R (1994) Pleasure-arousal theory and the intensity of emotions. J Pers Soc Psychol 67:525-539

Revell VL, Arendt J, Fogg LF, Skene DJ (2006) Alerting effects of light are sensitive to very short wavelengths. Neurosci Lett 399:96-100

Rogers PJ (2007) Caffeine, mood and mental performance in everyday life. Nutr Bull 32:84-89

Rüger M, Gordijn MCM, Beersma DGM, de Vries B, Daan S (2006) Time-of-day-dependent effects of bright light exposure on human psychophysiology: comparison of daytime and nighttime exposure. American Journal of Physiology — Regulatory. Integr Comp Physiol 290:R1413-R1420

Ruusunen A, Lehto SM, Tolmunen T, Mursu J, Kaplan GA, Voutilainen S (2010) Coffee, tea and caffeine intake and the risk of severe depression in middle-aged Finnish men: the Kuopio Ischaemic Heart Disease Risk Factor Study. Public Health Nutr 13:1215-1220

Sicard BA, Perault MC, Enslen M, Chauffard F, Vandel B, Tachon P (1996) The effects of $600 \mathrm{mg}$ of slow release caffeine on mood and alertness. Aviat Space Environ Med 67:859-862

Skinner TL., Jenkins DG., Leveritt MD., McGorm A., Bolam KA., Coombes JS. et al (2013) Factors influencing serum caffeine concentrations following caffeine ingestion. Journal of Science and Medicine in Sport

Smit HJ, Rogers PJ (2000) Effects of low doses of caffeine on cognitive performance, mood and thirst in low and higher caffeine consumers. Psychopharmacology 152:167-173

Smith A (2009) Effects of caffeine in chewing gum on mood and attention. Hum Psychopharmacol: Clin Exp 24:239-247

Smith A, Sutherland D, Christopher G (2005) Effects of repeated doses of caffeine on mood and performance of alert and fatigued volunteers. $\mathrm{J}$ Psychopharmacol 19:620-626

Vandewalle G, Balteau E, Phillips C, Degueldre C, Moreau V, Sterpenich $\mathrm{V}$ et al (2006) Daytime light exposure dynamically enhances brain responses. Curr Biol 16:1616-1621

Vandewalle G, Gais S, Schabus M, Baleau E, Carrier J, Darsaud A et al (2007) Wavelength-dependent modulation of brain responses to a working memory test by daytime light exposure. Cereb Cortex 17: $2788-2795$

Västfjäll D, Gärling T (2007) Validation of a Swedish short self-report measure of core affect. Scand J Psychol 48:233-238

Västfjäll D, Friman M, Gärling T, Kleiner M (2002) The measurement of core affect: a Swedish self-report measure derived from the affect circumplex. Scand J Psychol 43:19-31 
Viola AU, James LM, Schlangen LJ, Dijk DJ (2008) Blue-enriched white light in the workplace improves self-reported alertness, performance and sleep quality. Scand J Work, Environ Health 34:297-306

Walch JM, Rabin BS, Day R, Williams JN, Choi K, Kang JD (2005) The effect of sunlight on postoperative analgesic medication use: a prospective study of patients undergoing spinal surgery. Psychosom Med 67:156-163

Warburton DM, Bersellini E, Sweeney E (2001) An evaluation of a caffeinated taurine drink on mood, memory and information processing in healthy volunteers without caffeine abstinence. Psychopharmacology 158:322-328

Winston AP, Hardwick E, Jaberi N (2005) Neuropsychiatric effects of caffeine. Adv Psychiatr Treat 11:432-439
Wood B, Rea MS, Plitnick B, Figueiro MG (2013) Light level and duration of exposure determine the impact of self-luminous tablets on melatonin suppression. Appl Ergon 44:237-240

Wright KP Jr, Badia P, Myers B, Plenzler S (1997) Combination of bright light and caffeine as a countermeasure for impaired alertness and performance during extended sleep deprivation. J Sleep Res 6:26-35

Wright KP Jr, Myers BL, Plenzler SC, Drake CL, Badia P (2000) Acute effects of bright light and caffeine on nighttime melatonin and temperature levels in women taking and not taking oral contraceptives. Brain Res 873:310-317

Zaidi FH, Hull JT, Peirson SN, Wulff K, Aeschbach D, Gooley JJ et al (2007) Short-wavelength light sensitivity of circadian, pupillary, and visual awareness in humans lacking an outer retina. Curr Biol 17: $2122-2128$ 